Check for updates

Cite this: RSC Adv., 2017, 7, 39178

Received 7th June 2017

Accepted 3rd August 2017

DOI: $10.1039 / \mathrm{c} 7 \mathrm{ra0} 6352 \mathrm{k}$

rsc.li/rsc-advances

\section{A new 3D crosslinked polymer strategy for highly efficient oxygen reduction $\mathrm{Fe}-\mathrm{N}_{x} / \mathrm{C}$ catalysts $\dagger$}

\begin{abstract}
Zonggui Shao, ${ }^{\text {ab }}$ Lei Tong, ${ }^{\text {ab }}$ Yasheng Qian, ${ }^{\text {ab }}$ Rongmin Dun ${ }^{\text {ab }}$ and Wenmu Li (D) *a
The development of non-precious metal (NPM) catalysts with superior performance to replace $\mathrm{Pt} / \mathrm{C}$ is critical for the wide application of proton-exchange membrane fuel cells. In this work, a threedimensional crosslinked polymer with highly dispersed iron-nitrogen ( $\mathrm{Fe}-\mathrm{N}$ ) coordination units and a mechanically robust framework is designed, synthesized and used as the sole precursor to obtain Fecoordinated nitrogen-doped carbon $\left(\mathrm{Fe}-\mathrm{N}_{x} / \mathrm{C}\right)$ oxygen reduction reaction (ORR) catalysts. After optimization of the pyrolysis conditions and the use of $\mathrm{SiO}_{2}$ templates to modify the catalyst nanostructure, a highly active catalyst of T-FeNC-800R is obtained, which exhibits a high half-wave potential of $751 \mathrm{mV}$ in $0.1 \mathrm{M} \mathrm{HClO}_{4}$. Besides, the T-FeNC-800R catalyst has an excellent ORR activity with onset and half-wave potentials of 1030 and $873 \mathrm{mV}$ in $0.1 \mathrm{M} \mathrm{KOH}$, respectively, which are higher than those of $\mathrm{Pt} / \mathrm{C}$ (onset and half-wave potentials are 1009 and $855 \mathrm{mV}$ vs. RHE, respectively). Moreover, this catalyst exhibits an almost four electron transfer process, high long-term stability, and better methanol tolerance than $\mathrm{Pt} / \mathrm{C}$ catalyst in acidic media. The excellent oxygen reduction reaction performance of T-FeNC-800R can be attributed to the mesoporous structure, high specific surface area and a large number of exposed active sites. Moreover, the effects of the $\mathrm{SiO}_{2}$ template, secondary pyrolysis and iron element on the catalytic performance are systematically discussed.
\end{abstract}

\section{Introduction}

Polymer electrolyte membrane fuel cells (PEMFCs) are considered as one of the most promising new energy systems for future stationary and mobile power generation due to their high energy density, high efficiency and zero emissions. ${ }^{1-4}$ However, the cathode suffers from relatively sluggish ORR kinetics and therefore high overpotential, which limits the performance of PEMFCs. ${ }^{5}$ To date, platinum (Pt) or Pt-based catalysts are widely used for cathodic materials owing to having the best catalytic activity for ORR. ${ }^{6}$ Unfortunately, the prohibitively high cost, poor stability and serious intermediate intolerance, such as $\mathrm{CO}$ poisoning and methanol crossover, severely hinders the practical use of PEMFCs. ${ }^{7,8}$ Therefore, great efforts have been directly devoted to searching for alternative non-precious metals or even metal-free species catalysts to substitute the Ptbased catalysts over the past decades. ${ }^{9-12}$ Among them, the iron-based (Fe-based) catalysts were regarded as a promising alternative to Pt-based catalysts for the ORR. ${ }^{13-16}$

Although the significant progresses have been persistently achieved in Fe-based electrocatalysts, the inefficiently traditional

${ }^{a}$ Key Laboratory of Optoelectronic Materials Chemistry and Physics, Fujian Institute of Research on the Structure of Matter, Chinese Academy of Sciences, Fuzhou 350002, P. R. China.E-mail:liwm@fjirsm.ac.cn

${ }^{b}$ University of Chinese Academy of Sciences, Beijing 100049, China

$\dagger$ Electronic supplementary information (ESI) available. See DOI: 10.1039/c7ra06352k trial and error experiment approach was still the main ways for the R\&D of Fe-based catalysts. ${ }^{\mathbf{8} 17}$ This is because most of high performance Fe-based catalysts obtained were subjected to high temperature pyrolysis, making them extremely difficult to tailor the structure and surface properties, letting alone the identification of the nature of Fe-based catalysts active sites. ${ }^{18}$ Quite recently, a number of studies have been focused on the identification of the active sites structure of Fe-based catalysts. Although further confirmation is needed, it is reported that the highly plausible active site structures of Fe-based catalysts was the iron ions attaching to the carbon through coordinating with nitrogen moieties. ${ }^{19-22}$ One possible method to resolve these challenges is to synthesize a novel precursor with a high content of thermally stable nitrogen, and with a structure that can readily coordinate with iron, generating well-distributed Fecoordinated nitrogen $\left(\mathrm{Fe}-\mathrm{N}_{x}\right)$ sites prior to pyrolysis. Besides purposely selecting and designing precursors containing large numbers of potential active sites, the optimization of catalyst nanostructure is also critical to obtain highly ORR active $\mathrm{Fe}-\mathrm{N}_{x} / \mathrm{C}$ catalysts. Efficient ORR can be only achieved by continuously transferring protons, oxygen molecules and electrons to active sites through the favorable percolation networks. ${ }^{23}$ Herein, the suitable mesoporous structure and high conductivity properties are of significance for their high performance Fe-based catalysts. ${ }^{24}$ Besides, the mesoporous structure is also helpful to increase the specific surface area of the catalyst and make the active sites accessible to reactants. ${ }^{25,26}$ 
In this work, a three-dimensional crosslinked polymer was designed, synthesized and used as the solely precursor. This polymer consists of alternating rigid aromatic imide segments and triphenanthroline-coordinated ferrous ions. The high carbon residue aromatic polyimides are deliberately utilized to keeping all ferrous ions well separated initially, which could effectively prevent ferrous ions form sintering during pyrolysis even under high initial iron content and thus create high active sites density Fe-based catalysts. ${ }^{27-30}$ In order to further enhance the ORR performance of Fe-based catalysts, $\mathrm{SiO}_{2}$ nanoparticles was introduced as a template to create more favorable mesoporous structure and percolation properties. Highly active mesoporous ORR catalysts were successfully prepared and the influencing factors of catalyst performance were systematically discussed.

\section{Experimental}

\section{Synthesis of catalysts}

The $\mathrm{FeBr}_{2}$ (98\%), 2,2'-bis-(3,4-dicarboxyphenyl) hexafluoropropane dianhydride (6FDA) (98\%) and $20 \mathrm{wt} \% \mathrm{Pt} / \mathrm{C}$ were purchased from Alfa Aesar (China) Chemical Co., Ltd. (Shanghai, China); the 1,10-phenanthroline monohydrate (99\%) was purchased from Sinopharm Chemical Reagent Co., Ltd. (Shanghai, China) and used without further purification. The 5-nitro-1,10-phenanthroline and 5-amino-1,10-phenanthroline were prepared according to the reported literature. ${ }^{31,32}$ The bisPhen/6FDA was obtained from the 5-amino-1,10phenanthroline and 6FDA and the structure of bisPhen/6FDA was verified by $\mathrm{H} 1 \mathrm{NMR}$ (Fig. S1 and $\mathrm{S} 2 \dagger$ ). ${ }^{33}$ The mixture of 15 and $50 \mathrm{~nm}$ silicon spheres at the rate of $1: 1$ in mass were used for hard template $\left(\mathrm{SiO}_{2}\right)$. The catalysts were prepared by homogeneously dispersing iron and bisPhen/6FDA precursors onto the surface of $\mathrm{SiO}_{2}$. In a typical synthesis process as shown in Scheme 1, $240 \mathrm{mg}$ ( $0.3 \mathrm{mmol})$ bisPhen/6FDA was dissolved in 5 $\mathrm{mL} \mathrm{DMF}$ and $720 \mathrm{mg}$ of $\mathrm{SiO}_{2}$ was added under magnetic stirring. Then $1 \mathrm{~mL}$ DMF solution containing $43 \mathrm{mg}$ ( $0.2 \mathrm{mmol}) \mathrm{FeBr}_{2}$ was added under stirring conditions, the reaction mixture was heated to $80{ }^{\circ} \mathrm{C}$ and was stirred for $1 \mathrm{~h}$. A gel was obtained after cooling and this gel was scraped into water then was crushed,

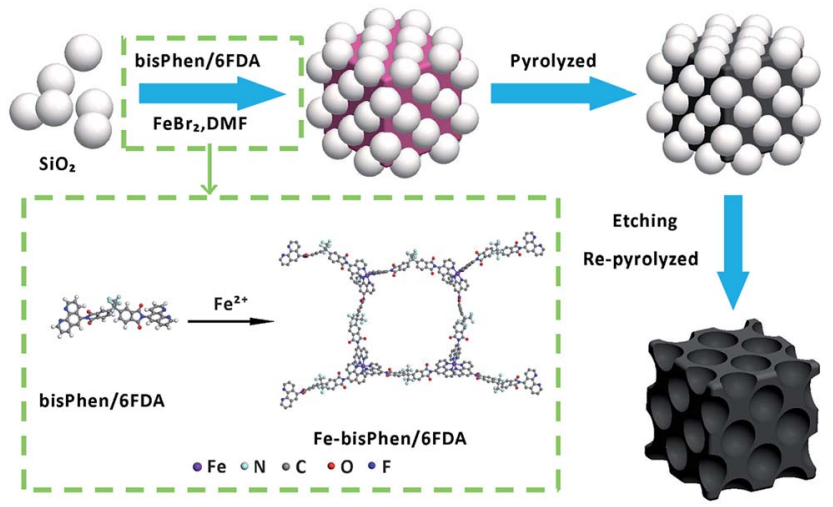

Scheme 1 The schematic illustration of the synthesis of mesoporous FeNC catalyst. the precipitate was filtered off and washed with water and methanol, then drying under a vacuum at $85{ }^{\circ} \mathrm{C}$ for 6 hours. The resulting solid was heat treated under nitrogen at $800{ }^{\circ} \mathrm{C}$ for $2 \mathrm{~h}$ with temperature ramp rates of $10{ }^{\circ} \mathrm{C} \mathrm{min}^{-1}$. Finally, the $\mathrm{SiO}_{2}$ was leached out using excess amounts of $40 \mathrm{wt} \%$ hydrofluoric acid (HF) to obtain the T-FeNC-800 catalyst. The T-FeNC-800 catalyst was re-pyrolyzed at $900{ }^{\circ} \mathrm{C}$ for 3 hours under a nitrogen atmosphere to form the T-FeNC-800R catalyst (Fig. S4 $\dagger$ ). The detailed synthesis parameters for each sample prepared in this work was listed in Table S1. $\dagger$

\section{Sample characterization}

The proton nuclear magnetic resonance (1H NMR) spectra was recorded on a $400 \mathrm{MHz}$ spectrometer. The thermogravimetric (TG) analysis of Fe-bisPhen/6FDA and Fe-phenanthroline was carried out in a range from $30-1000{ }^{\circ} \mathrm{C}$ under nitrogen atmosphere with a heating rate of $10{ }^{\circ} \mathrm{C} \mathrm{min}^{-1}$. Transmission election microscopy (TEM) was performed using a JEM-2010 (JEOL Ltd, Japan) operating at $200 \mathrm{kV}$. The Brunauer-Emmett-Teller (BET) method was used to determine the specific surface area by measuring the adsorption of $\mathrm{N}_{2}$ using an ASAP2020 volumetric adsorption analyzer (Micromeritics, U.S.A.). The specific surface area was determined by the standard BET method in a relative pressure range of $0.05-0.2$, the pore size distribution curves of micropores and mesopores was calculated by the HorvathKawazoe (HK) method and by the Barrett-Joyner-Halenda (BJH) method, respectively. Before measurements, all samples were degassed at $120{ }^{\circ} \mathrm{C}$ for at least $10 \mathrm{~h}$. Raman spectra was collected on a LabRAM HR (Horiba Jobin Yvon, Ltd., France) with a $532 \mathrm{~nm}$ laser excitation. Surface analysis of the catalyst particles was carried out using an XPS on a VG Scientific ESCALAB MK II using $\mathrm{Al} \mathrm{K} \alpha$ radiation $(1486.71 \mathrm{eV})$ and the $\mathrm{C} 1 \mathrm{~s}$ peak at $284.8 \mathrm{eV}$ as the internal standard. Powder X-ray diffraction (XRD) patterns were performed with a MiniFlex-II diffractometer (Rigaku, Japan) using a $\mathrm{Cu} \mathrm{K} \alpha$ radiation source.

\section{Electrochemical measurements}

For rotating disk electrode (RDE) and rotating ring disk electrode (RRDE) measurements, catalyst ink was prepared by sonicating $4 \mathrm{mg}$ of catalyst in $985 \mu \mathrm{L}$ of ethanol and $38 \mu \mathrm{L}$ of $5 \mathrm{wt} \%$ Nafion solution for $60 \mathrm{~min}$. Then, $20 \mu \mathrm{L}$ of ink was deposited on the rotating disk electrode (RDE, $5 \mathrm{~mm}$ diameter, $0.196 \mathrm{~cm}^{2}$ geometric surface areas) and $25 \mu \mathrm{L}$ of ink was deposited on the rotating ring-disk electrode (RRDE, E7R9, disk area: $0.2475 \mathrm{~cm}^{2}$, Pt ring area: $0.1866 \mathrm{~cm}^{2}$ ), respectively. The catalyst loading on RDE or RRDE was $0.4 \mathrm{mg} \mathrm{cm}^{-2}$. Commercially available Pt/C catalyst (Alfa Aesar, 20 wt\% Pt) was measured for comparison. $4 \mathrm{mg} \mathrm{Pt} / \mathrm{C}$ was dispersed in $2 \mathrm{~mL}$ ethanol and $38 \mu \mathrm{L}$ of $5 \mathrm{wt} \%$ Nafion solution and then sonicated for $60 \mathrm{~min}$, and the ink was drop coated onto the glassy carbon disk of $\operatorname{RDE}(10 \mu \mathrm{L})$ and $\operatorname{RRDE}(12.5 \mu \mathrm{L})$. The Pt/C catalyst loading on RDE or RRDE was $20 \mu \mathrm{g} \mathrm{Pt} \mathrm{cm}^{-2}$. A conventional three-electrode cell was employed incorporating an $\mathrm{Ag} / \mathrm{AgCl}$ as the reference electrode, a Pt wire as the counter electrode and the RDE or RRDE as the working electrode, the electrolyte was $0.1 \mathrm{M} \mathrm{HClO}_{4}$ solution. In all test results, the potentials were 
converted to values versus the reversible hydrogen electrode (RHE). The conversion from $\mathrm{Ag} / \mathrm{AgCl}$ to $\mathrm{RHE}$ is done by measuring the voltage $\Delta E$ between the $\mathrm{Ag} / \mathrm{AgCl}$ and a Pt-black coated Pt wire immersed in $0.1 \mathrm{M} \mathrm{HClO}_{4}$ or $0.1 \mathrm{M} \mathrm{KOH}$ saturated with $\mathrm{H}_{2}$, the measured $\Delta E$ was $0.267 \mathrm{~V}$ in $0.1 \mathrm{M} \mathrm{HClO}_{4}$ and $0.94 \mathrm{~V}$ in $0.1 \mathrm{M} \mathrm{KOH}$, respectively (Fig. S5 and S6†). LSV measurements were carried out in $\mathrm{N}_{2}$ - or $\mathrm{O}_{2}$-saturated $0.1 \mathrm{HClO}_{4}$ or $0.1 \mathrm{M} \mathrm{KOH}$ solution, at a scan rate of $10 \mathrm{mV} \mathrm{s}^{-1}$. LSV measurements in the RRDE were carried out in $\mathrm{N}_{2}$ - or $\mathrm{O}_{2}$-saturated $0.1 \mathrm{HClO}_{4}$ solution at a scan rate of $10 \mathrm{mV} \mathrm{s}^{-1}$ also, a potential of the Pt ring disk was set to $1.2 \mathrm{~V} v s$. RHE. Before each measurement, the solution was bubbled with $\mathrm{N}_{2}$ or $\mathrm{O}_{2}$ gas for $30 \mathrm{~min}$, and the working electrode was activated by sweeping between 0.2 and $1.4 \mathrm{~V}$ at a scan rate of $50 \mathrm{mV} \mathrm{s}^{-1}$ for $10 \mathrm{~min}$. Corrected oxygen reduction currents were obtained by subtracting the background current obtained for the $\mathrm{N}_{2}$-saturated solution from the measured current obtained for the $\mathrm{O}_{2}$-saturated solution. For the methanol crossover study, the current was recorded at $0.667 \mathrm{~V}$ vs. RHE with an RDE rotation rate of $900 \mathrm{rpm}$, with $1 \mathrm{M}$ methanol being added into the $\mathrm{O}_{2}$-saturated electrolyte around $300 \mathrm{~s}$. The lifetime stability test was carried out with 10000 cycles in the potential window of 0.6 to $1.0 \mathrm{~V} v \mathrm{~s}$. $\mathrm{RHE}$ in $\mathrm{O}_{2}$-saturated electrolyte with the scan rate of $50 \mathrm{mV} \mathrm{s}^{-1}$ on stationary electrode. After performing 10000 stability test cycles, corresponding LSV was recorded to compare the final activity with initial activity of the samples. For this purpose, the $E_{1 / 2}$ before and after the stability test were compared. The hydrogen peroxide yield $\left(\mathrm{H}_{2} \mathrm{O}_{2}(\%)\right)$ and the electron transfer number $(n)$ calculated from the RRDE measurement was based on the disk current $\left(I_{\mathrm{D}}\right)$ and ring current $\left(I_{\mathrm{R}}\right)$ via the following equation:

$$
\begin{aligned}
& \mathrm{H}_{2} \mathrm{O}_{2}=\frac{2 I_{\mathrm{R}}}{N\left|I_{\mathrm{D}}\right|+I_{\mathrm{R}}} \times 100 \\
& n=4-\left(2 \frac{\mathrm{H}_{2} \mathrm{O}_{2}(\%)}{100}\right)
\end{aligned}
$$

where $N=0.37$ is the current collection efficiency of Pt ring.

\section{Results and discussion}

The T-FeNC-800R catalyst was synthesized by mixing the FebisPhen/6FDA and spherical silica template in solution, followed by heat treating at $800{ }^{\circ} \mathrm{C}$, hydrofluoric acid (HF) etching, and a second heat treating at $900{ }^{\circ} \mathrm{C}$ (Scheme 1). The microscopic structure of T-FeNC-800R was evaluated by transmission election microscopy (TEM) as shown in Fig. 1. Some disordered spherical mesopores were clearly observed in the T-FeNC-800R (Fig. 1b). This is a result of the vacation of silica during $\mathrm{HF}$ etching. As shown in Fig. 1c, most graphite nanosheets were crimped and arranged irregularly, suggesting the poor crystallization of the carbon frameworks in the resulting products. Furthermore, the selected-area electron diffraction (SAED) pattern in the Fig. 1d also confirmed the poor graphite crystallinity of T-FeNC-800R. ${ }^{34}$

In order to reveal the effect of secondary pyrolysis and silicon template on the activity of the catalyst, we also prepared FeNC-
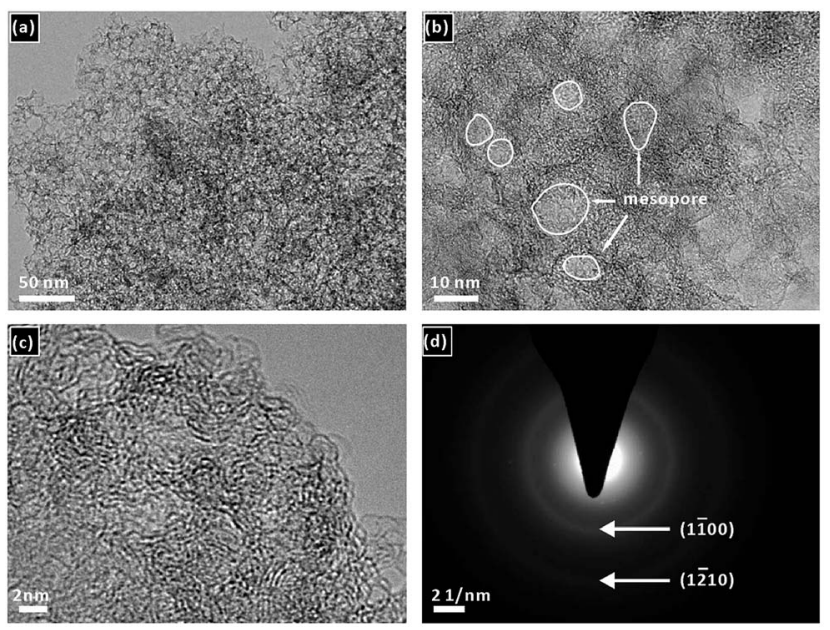

Fig. 1 (a) and (b) TEM and (c) HRTEM images of T-FeNC-800R; (d) the electron diffraction pattern of T-FeNC-800R.

800R (without template) and T-FeNC-800 (use template but undergoes only one pyrolysis at $800{ }^{\circ} \mathrm{C}$ ). The X-ray diffraction (XRD) patterns and Raman spectroscopy were performed to determine the crystal structure of our catalysts (Fig. S7 and S8 $\dagger$ ). The peaks around $2 \theta=26^{\circ}$ assigning to (002) diffraction peaks of graphitic carbons and the peak at $44^{\circ}$ corresponding to (100) plane of graphitic carbon. ${ }^{35}$ As shown in Fig. S7, $\dagger$ both catalysts (T-FeNC-800 and T-FeNC-800R) prepared with silicon template exhibited much lower intensity of (002) and (100) peaks than those of FeNC-800R prepared without template, which indicated that the introduction of silicon template can hinder the graphitization in the whole structure of the catalyst. Moreover, this conclusion can also be verified by the analysis of Raman spectroscopy. The ratio of the $\mathrm{D}$ and $\mathrm{G}$ band intensities $\left(I_{\mathrm{D}} / I_{\mathrm{G}}\right)$ in Raman spectroscopy was often used to evaluating the degree of graphitization of carbon frameworks, the higher the ratio of $I_{\mathrm{D}} /$ $I_{\mathrm{G}}$, the smaller the degree of graphitization. ${ }^{36}$ As Fig. S $\$$ showed, two prominent peaks corresponding to the $\mathrm{D}$ band (about $1360.0 \mathrm{~cm}^{-1}$ ) and $\mathrm{G}$ band (about $1584.9 \mathrm{~cm}^{-1}$ ) were observed in these samples. FeNC-800R (1.41) exhibited a much smaller $I_{\mathrm{D}} / I_{\mathrm{G}}$ value than T-FeNC-800R (3.00) and T-FeNC-800 (3.13), which can jump to the same conclusion as that of XRD.

The nitrogen sorption measurements were performed to investigate the specific surface area and pore size of the catalysts. The $\mathrm{N}_{2}$ adsorption/desorption isotherm and pore size distribution from the Barrett-Joyner-Halenda (BJH) model were shown in Fig. 2a and b, respectively. It's worth noting that FeNC800R without any template display a near $390 \mathrm{~m}^{2} \mathrm{~g}^{-1}$ high specific surface area. Meanwhile, the typical mesoporous property was also observed in FeNC-800R according to its feature of type IV isotherm (Fig. 2a). ${ }^{37}$ In fact, this decent nanostructure of FeNC-800R can be solely attributed to the special structure of our designed precursor. On the one hand, the three-dimensional crosslinked polymer itself has the porous property. On the other hand, the trifluoromethyl groups in the structure of our precursor may decomposed at high temperature to form gas fluoride molecules thus to create more specific 
(a)
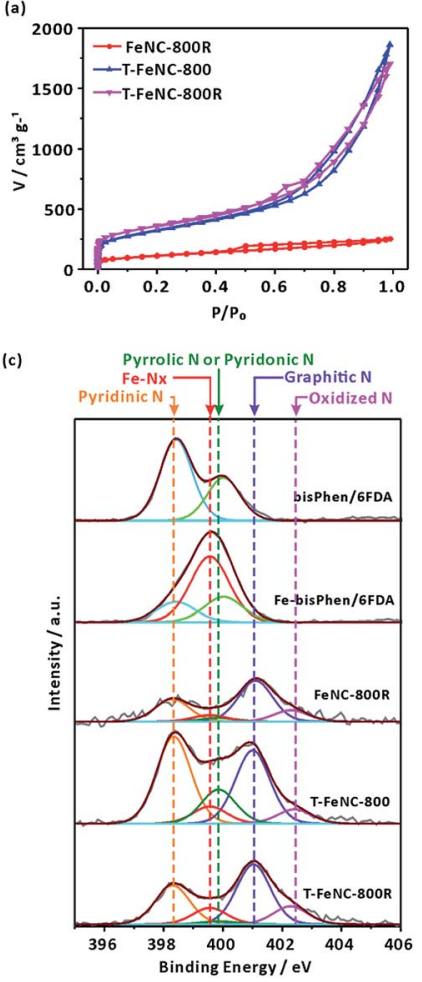

(b)

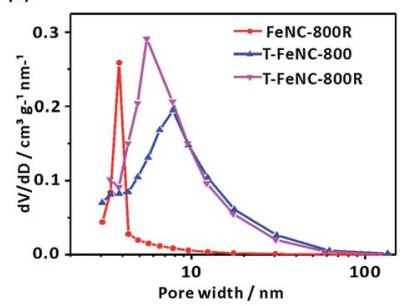

(d)

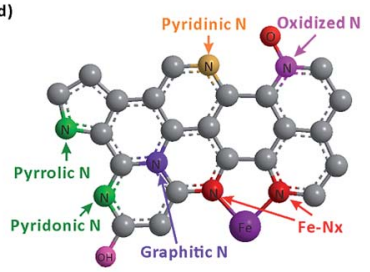

(e)

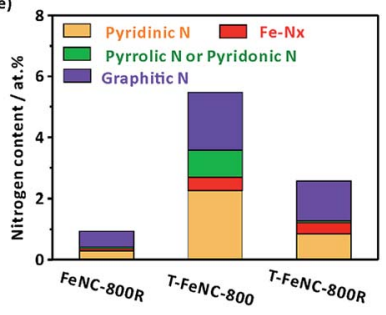

Fig. 2 (a) $\mathrm{N}_{2}$ adsorption-desorption isotherms and (b) the pore size distribution of catalysts. (c) N 1s XPS spectra of different sample. (d) Schematic illustration of different nitrogen species. (e) Content of different $\mathrm{N}$ species in FeNC-800R, T-FeNC-800 and T-FeNC-800R

surface area. However, both the drying procedure of precursor from a gel state to a powder state (Fig. S4 $\dagger$ ) and the subsequent pyrolysis treatment of the powder were suspected to break the pore structure of the precursor. This resulted in limiting the mesoporous volume $\left(0.357 \mathrm{~cm}^{3} \mathrm{~g}^{-1}\right)$ and distribution (average pore size of $3.82 \mathrm{~nm}$ ) of FeNC-800R. Both T-FeNC-800 and T-FeNC-800R showed much more favorable nanostructure than that of FeNC-800R, which clearly demonstrated the positive effects of nano silica template. Although the mesoporous volume and pore size of T-FeNC-800R are slight lower relative to T-FeNC-800 (Table $\mathrm{S} 2 \dagger$ ), the microporous specific surface area and content of T-FeNC-800R increases after second pyrolysis. This is due to the partial collapsing of mesopores and the volatilization of some small molecules (such as $\mathrm{C}_{x} \mathrm{~N}_{y}, \mathrm{NO}_{x}, \mathrm{CO}_{2}$, $\mathrm{CH}_{x}$, etc.) during the second pyrolysis process. ${ }^{38}$

X-ray photoelectron spectroscopy (XPS) measurement was performed to analyze the elemental compositions of the catalysts (Table S3†). It's interesting that the nitrogen content of the FeNC-800R is as low as $1.09 \%$, which is much lower than that of T-FeNC-800 (5.52\%) and T-FeNC-800R (2.97\%). There are a number of factors that should be responsible for this result, and the low porosity of FeNC-800R is the most important one, which can't expose enough specific surface area and nitrogen for the XPS detection. To further explore how the Fe-based preparing procedures affect the evolution of nitrogen, the high-resolution $\mathrm{N}$ 1s spectra of catalysts was performed. The bisPhen/6FDA and Fe-bisPhen/6FDA monomers were utilized as

model compounds to verify the binding energy of iron-nitrogen coordination $\left(\mathrm{Fe}-\mathrm{N}_{x}\right)$. The $\mathrm{N}$ 1s curve of bisPhen/6FDA patently showed two peaks at 398.42 and $400.02 \mathrm{eV}$ (Fig. 2c), which was ascribed to two distinct nitrogen bonding environments (Fig. S11a $\dagger$ ). Accordingly, the $\mathrm{N}$ 1s curve of Fe-bisPhen/6FDA could be divided into three peaks at 398.42, 399.56 and $400.02 \mathrm{eV}$, which are assignable to three distinct nitrogen bonding environments (Fig. S11 $\mathrm{b}_{\dagger} \dagger$ ). By comparing the $\mathrm{N} 1 \mathrm{~s}$ curve of bisPhen/6FDA and Fe-bisPhen/6FDA, the peak at $399.56 \mathrm{eV}$ of Fe-bisPhen/6FDA could be safely assigned to the pyridinic nitrogens directly attaching to ferrous ions $\left(\mathrm{Fe}-\mathrm{N}_{x}\right)$ (Fig. S11b $\dagger)^{20}$ The high-resolution $\mathrm{N}$ 1s spectra of catalysts could be deconvoluted into five peaks, which corresponded to pyridinic $\mathrm{N}(398.30 \mathrm{eV}), \mathrm{Fe}-\mathrm{N}_{x}(399.56 \mathrm{eV})$, pyrrolic $\mathrm{N}$ or pyridonic $\mathrm{N}(399.85 \mathrm{eV})$, graphitic $\mathrm{N}(401.03 \mathrm{eV})$ and oxidized $\mathrm{N}$ (402-403 eV), respectively (Fig. 2d). ${ }^{\mathbf{1 2 , 2 8 , 3 9}}$ All types nitrogen in T-FeNC-800R decreased comparing to those of T-FeNC-800 after the second pyrolysis (Fig. 2e). Especially, the signal assignable to pyrrolic $\mathrm{N}$ or pyridonic $\mathrm{N}$ of catalyst T-FeNC-800R was hardly observed. Two peaks 710.9 and $713.2 \mathrm{eV}$ assignable to the $\mathrm{N}$-coordinated $\mathrm{Fe}^{2+}$ and $\mathrm{Fe}^{3+}$ species were also observed in the corresponding Fe 2p XPS spectra (Fig. S12†), which clearly showed the presence of $\mathrm{Fe}$ in the catalysts. ${ }^{\mathbf{4 0}}$

The ORR activity of prepared catalysts was assessed using rotating disk electrode (RDE) in $0.1 \mathrm{M} \mathrm{HClO}_{4}$ solution. The optimum pyrolysis condition for ORR activity was studied by only changing pyrolysis temperatures, $\mathrm{SiO}_{2}$ template, and second pyrolysis at $900{ }^{\circ} \mathrm{C}$. The best ORR Fe-based catalysts were realized at the first pyrolysis temperature of $800{ }^{\circ} \mathrm{C}$ and the second pyrolysis temperature of $900{ }^{\circ} \mathrm{C}$ (Fig. S13 $\dagger$ ). The structure feature of the precursor made FeNC-800R exhibit the characteristic of mesoporous materials, but the limited percolation channels which is not favor in increasing its ORR activity $\left(E_{1 / 2}=624 \mathrm{mV} v s\right.$. RHE) (Fig. 3a). As Fig. 3a showed, the ORR activity only enhance $4 \mathrm{mV}$ from catalyst FeNC-800R to T-FeNC800 after the introduction of silica template, though their BET surface area increase from FeNC-800R $\left(390 \mathrm{~m}^{2} \mathrm{~g}^{-1}\right)$ to T-FeNC$800\left(1135 \mathrm{~m}^{2} \mathrm{~g}^{-1}\right)$. This strongly indicated that the ORR activity of Fe-based catalysts could not be enhanced simply by increasing their surface area and the nitrogen content. To further improving the ORR activity of our Fe-based catalysts, the second pyrolysis procedure was introduced. The T-FeNC-800R exhibited a $123 \mathrm{mV}$ half-wave potential increase to $751 \mathrm{mV} v s$. RHE comparing to T-FeNC-800, and only $31 \mathrm{mV}$ negative than that of $\mathrm{Pt} / \mathrm{C}\left(E_{1 / 2}=782 \mathrm{mV}\right.$ vs. RHE). Moreover, when switching to the alkaline media, the $E_{1 / 2}$ and $E_{\text {onset }}$ of T-FeNC-800R were $873 \mathrm{mV}$ and $1030 \mathrm{mV}$, respectively, both of which higher than those of $\mathrm{Pt} / \mathrm{C}\left(E_{1 / 2}=855 \mathrm{mV}\right.$ and $E_{\text {onset }}=1009 \mathrm{mV} v s$. RHE $)$ (Fig. 3a). This excellent result was also comparable to other nonprecious catalysts (Table $\mathrm{S} 4 \dagger$ ). The significant improvement of the T-FeNC-800R's ORR activity may be attributed to the increasing of the density of highly active $\mathrm{Fe}-\mathrm{N}_{x}$ sites and the purity of Fe-based catalyst. Although the exact chemical structure of Fe-based catalysts' active sites is still an unsolved puzzle, it's well document that highly active sites of Fe-based catalysts derived mainly from the micropores..$^{25,41,42}$ Indeed, the specific surface area of T-FeNC-800R's micropores are almost double 

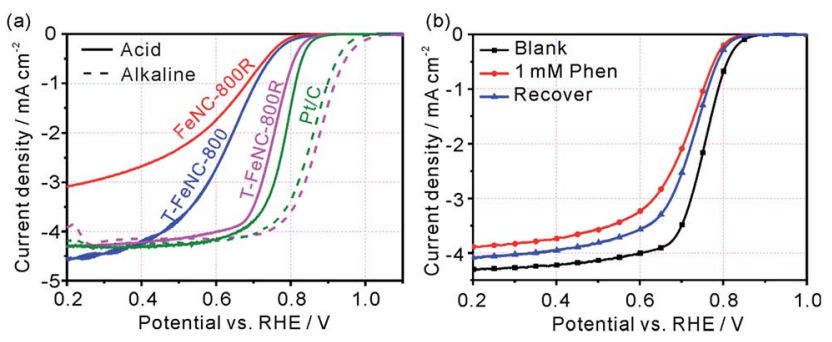

(c)

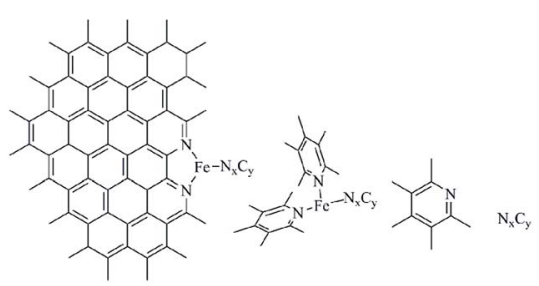

Fig. 3 (a) RDE results of FeNC-800R, T-FeNC-800, T-FeNC-800R and $\mathrm{Pt} / \mathrm{C}$ in $\mathrm{O}_{2}$-saturated $0.1 \mathrm{M} \mathrm{HClO}_{4}$ (full line) and $0.1 \mathrm{M} \mathrm{KOH}$ (imaginary line) at $900 \mathrm{rpm}$ with a scan rate of $10 \mathrm{mV} \mathrm{s}^{-1}$. (b) RDE results (in $\mathrm{O}_{2}$-saturated $0.1 \mathrm{M} \mathrm{HClO}_{4}$ at $900 \mathrm{rpm}$, with a scan rate of $10 \mathrm{mV} \mathrm{s}^{-1}$ ) of T-FeNC-800R (without and with 1,10-phenanthroline). (c) Schematic illustration of the highly active $\mathrm{Fe}-\mathrm{N}_{x} / \mathrm{C}$ species and possible nitrogen containing small fragments.

after second pyrolysis comparing to T-FeNC-800 (Table S2 $\dagger$ ), though the content of nitrogen assignable to the $\mathrm{Fe}-\mathrm{N}_{x}$ decreased from $0.45 \%$ to $0.36 \%$ (Table S3†). The purity of Fe-based catalysts is also a key factor to affect their ORR activity. Our catalysts system should be very complicated since all of them resorted to high temperature pyrolysis. However, they should contain the highly active $\mathrm{Fe}-\mathrm{N}_{x} / \mathrm{C}$ species and the active $\mathrm{N}$ species at least (Fig. 3c). Some nitrogen active species may attach to a very small fragment of graphene sheet, which may be dissolvable in acid solution. These dissolvable nitrogen containing small fragments $\mathrm{N}_{x} \mathrm{C}_{y}$ may further react with highly active $\mathrm{Fe}-\mathrm{N}_{x} / \mathrm{C}$ species and disable them to ORR under the acid leaching condition. To prove our assumption, 1,10-phenanthroline (Phen) was used as a model compound to test how the soluble nitrogen containing fragment affects the ORR activity of Fe-based catalysts. The Phen test was performed by the method of the LSV without and with adding $1 \mathrm{mM}$ Phen to $0.1 \mathrm{M} \mathrm{HClO}_{4}$. The $E_{1 / 2}$ of T-FeNC-800R catalyst negatively shifted by $43 \mathrm{mV}$ after the adding of $1 \mathrm{mM}$ Phen. However, the ORR activity of T-FeNC-800R didn't recovered even after the catalyst was multiply washed with de-ions water to remove Phen (Fig. 3b). This clearly demonstrated the destructive effect of nitrogen containing impurity for the ORR. The second pyrolysis which can remove ORR inactive impurities $\left(\mathrm{C}_{x} \mathrm{~N}_{y}, \mathrm{C}-\mathrm{F}, \mathrm{Fe}-\mathrm{F}, \mathrm{N}-\mathrm{O}\right.$, etc. $)$, recover the possible $\mathrm{Fe}-\mathrm{N}_{x} / \mathrm{C}$ active sites, and clean the electrochemical interface leading to more ORR active sites, may contribute the increase of the ORR activity. ${ }^{38,43}$ In fact, the almost disappearance of deconvolution signal assignable to the low or inactive pyrrolic and pyridonic $\mathrm{N}$ of $\mathrm{T}-\mathrm{FeNC}-800 \mathrm{R}$ after the second pyrolysis (Fig. 2e), ${ }^{12}$ clearly demonstrated the importance and necessity of second pyrolysis.

In order to further identify the true active species of our catalysts, the T-NC-800R catalyst without any iron ions was prepared according to the same synthetic procedure of T-FeNC800R. The ORR activity of T-NC-800R is much worse than that of T-FeNC-800R (Fig. 4a), though it possessed comparable high microporous specific surface areas and $\mathrm{N}$ content to the T-FeNC-800R (Tables S2 and S3†). The only different between the T-NC-800R and T-FeNC-800R is the possible highly active Fe- $\mathrm{N}_{x}$ species (Fig. 4b).

To confirm the importance of $\mathrm{Fe}-\mathrm{N}_{x}$ species for the ORR, an electrochemical poisoning test by NaSCN was also conducted. ${ }^{42-47}$ A sharp current density decrease was observed at $0.75 \mathrm{~V}$ after the adding $5 \mathrm{mM} \mathrm{SCN}^{-}$into the electrolyte (Fig. 4c). The corresponding LSV of T-FeNC-800R also exhibited a $95 \mathrm{mV}$ $E_{1 / 2}$ negatively shift. Besides, almost complete ORR activity recovery was observed after the complete removing of $\mathrm{SCN}^{-}$ ions (Fig. 4d). These results combined with XPS analysis strongly suggested that $\mathrm{Fe}-\mathrm{N}_{x}$ species are the highly active sites in the Fe-based catalysts.

To better understand the electrochemical catalytic behavior of T-FeNC-800R, its Tafel slope was calculated (Fig. 5a). It's obvious that a similar Tafel slope was observed for T-FeNC-800R (54 $\mathrm{mV}$ per decade) and $\mathrm{Pt} / \mathrm{C}$ (52 $\mathrm{mV}$ per decade). This means that the transfer of the first electron was probably the ratedetermining step in ORR catalyzed by T-FeNC-800R, which is similar to platinum-based materials. ${ }^{9}$ Furthermore, the $\mathrm{H}_{2} \mathrm{O}_{2}$ yield and electron transfer number $(n)$ have also been calculated by results of RRDE test (the potential of the Pt ring electrode was set to $1.2 \mathrm{~V} v s$. RHE). It could be seen from Fig. $5 \mathrm{~b}$ that the peroxide species yield of T-FeNC-800R was less than $7.58 \%$ and the electron-transfer number $(n)$ was higher than 3.85 in the measured potential range from 0.2 to $0.8 \mathrm{~V}$, which is close to the value of $\mathrm{Pt}$ (2.35\% and 3.96, respectively), suggesting the four
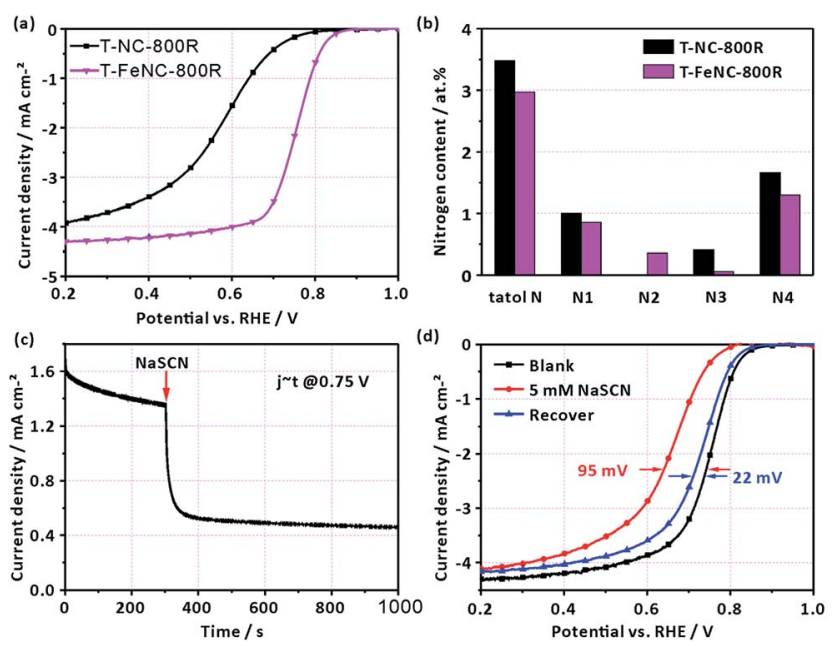

Fig. 4 (a) RDE results (in $\mathrm{O}_{2}$-saturated $0.1 \mathrm{M} \mathrm{HClO}_{4}$ at $900 \mathrm{rpm}$, with a scan rate of $10 \mathrm{mV} \mathrm{s}^{-1}$ ) of T-NC-800R and T-FeNC-800R. (b) Content of total $\mathrm{N}$, pyridinic $\mathrm{N}(\mathrm{N} 1), \mathrm{Fe}-\mathrm{N}_{x}(\mathrm{~N} 2)$, pyrrolic $\mathrm{N}$ or pyridonic $\mathrm{N}$ (N3), graphitic $\mathrm{N}$ (N4) in T-NC-800R and T-FeNC-800R. (c) Current-time $(I-t)$ curves of T-FeNC-800R on a rotating disk electrode $\left(900 \mathrm{rpm}\right.$ ) in $\mathrm{O}_{2}$-saturated $0.1 \mathrm{M} \mathrm{HClO}_{4}$ solution (without and with $\mathrm{SCN}^{-}$). (d) $\mathrm{RDE}$ results (in $\mathrm{O}_{2}$-saturated $0.1 \mathrm{M} \mathrm{HClO}_{4}$ at $900 \mathrm{rpm}$, with a scan rate of $10 \mathrm{mV} \mathrm{s}^{-1}$ ) of $\mathrm{T}-\mathrm{FeNC}-800 \mathrm{R}$ (without and with $\mathrm{SCN}^{-}$. 

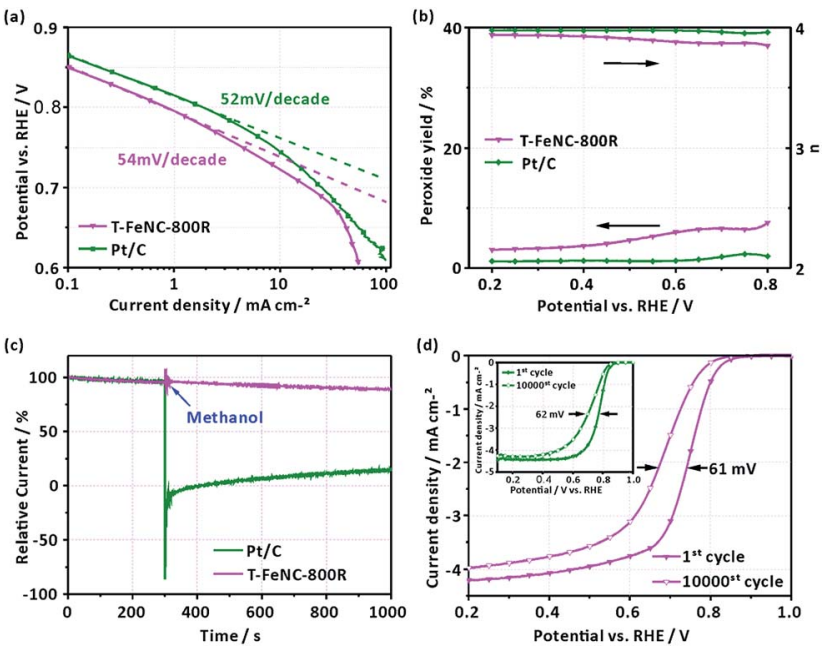

Fig. 5 (a) Tafel plots of T-FeNC-800R and Pt/C obtained from the RDE measurements. (b) $\mathrm{H}_{2} \mathrm{O}_{2}$ yield and electron-transfer number ( $n$ ) of $\mathrm{T}$-FeNC-800R and Pt/C. (c) Current-time $(I-t)$ curves of T-FeNC$800 \mathrm{R}$ and $\mathrm{Pt} / \mathrm{C}$ in $\mathrm{O}_{2}$-saturated $0.1 \mathrm{M} \mathrm{HClO}_{4}$ solution (without and with $1 \mathrm{M}$ methanol). (d) LSV of T-FeNC-800R and Pt/C (inset) before and after 10000 cycles in $\mathrm{O}_{2}$-saturated $0.1 \mathrm{M} \mathrm{HClO}_{4}$ solution. All tests on a rotating disk electrode $(900 \mathrm{rpm})$ with a scan rate of $10 \mathrm{mV} \mathrm{s}^{-1}$.

electron pathway of the ORR process for the T-FeNC-800R catalyst. The tolerance to methanol crossover and the stability of the catalyst material are also important parameters to be evaluated. The methanol-tolerance test was performed by the method of current-time $(I-t)$ plots with adding $1 \mathrm{M}$ methanol to $0.1 \mathrm{M} \mathrm{HClO}_{4}$ after about $300 \mathrm{~s}$ (at a potential of $0.667 \mathrm{~V} v s$. RHE). Like most of NPCs, the T-FeNC-800R clearly exhibits much better methanol-tolerance ability than that of Pt/C. The ORR stability of T-FeNC-800R was tested with 10000 cycles in the potential window of 0.6 to $1.0 \mathrm{~V} v \mathrm{vs}$. RHE at the scan rate of $50 \mathrm{mV} \mathrm{s}^{-1}$ on stationary electrode. After performing 10000 stability test cycles, the $E_{1 / 2}$ of T-FeNC-800R exhibited a $61 \mathrm{mV}$ negative potential shift, similar to the Pt/C (62 mV) (Fig. 5d), which suggested that the stability of the T-FeNC-800R was comparable to the $\mathrm{Pt} / \mathrm{C}$.

\section{Conclusion}

In this work, we have developed a high ORR active catalyst by pyrolysis the complex of $\mathrm{Fe}$ and bisPhen/6FDA using the $\mathrm{SiO}_{2}$ nanoparticles as template. The pyrolysis temperature largely affected the ORR activity, and the optimal catalyst T-FeNC-800R pyrolyzed at $800{ }^{\circ} \mathrm{C}$ exhibited an excellent ORR activity under both alkaline and acidic conditions. The $\mathrm{SiO}_{2}$ template played an important role on improving ORR activity via increasing the exposure of active sites of Fe-based catalysts and decreasing the diffusion resistance of ORR-relevant species (such as $\mathrm{O}_{2}$ and $\mathrm{H}_{2} \mathrm{O}$ ). The second pyrolysis after $\mathrm{HF}$ leaching was also an important step to achieve high ORR performance. Moreover, compare with the commercial Pt/C, the T-FeNC-800R exhibited similar stability and much better methanol tolerance in acidic media. As a result, our as-prepared T-FeNC-800R catalyst is a potentially viable alternative to precious $\mathrm{Pt} / \mathrm{C}$ catalyst in PEMFCs with high ORR performance and superior stability.

\section{Acknowledgements}

The authors gratefully acknowledge the financial support of the 100-Talent Program of Chinese Academy of Sciences, the NSFC (Project No. 21303206).

\section{References}

1 S. Guo, S. Zhang and S. Sun, Angew. Chem., Int. Ed., 2013, 52, 8526-8544.

2 R. Borup, J. Meyers, B. Pivovar, Y. S. Kim, R. Mukundan, N. Garland, D. Myers, M. Wilson, F. Garzon, D. Wood, P. Zelenay, K. More, K. Stroh, T. Zawodzinski, J. Boncella, J. E. McGrath, M. Inaba, K. Miyatake, M. Hori, K. Ota, Z. Ogumi, S. Miyata, A. Nishikata, Z. Siroma, Y. Uchimoto, K. Yasuda, K.-i. Kimijima and N. Iwashita, Chem. Rev., 2007, 107, 3904-3951.

3 F. Jaouen, E. Proietti, M. Lefevre, R. Chenitz, J.-P. Dodelet, G. Wu, H. T. Chung, C. M. Johnston and P. Zelenay, Energy Environ. Sci., 2011, 4, 114-130.

4 A. Morozan, B. Jousselme and S. Palacin, Energy Environ. Sci., 2011, 4, 1238.

5 W. Xia, A. Mahmood, Z. Liang, R. Zou and S. Guo, Angew. Chem., Int. Ed., 2016, 55, 2650-2676.

6 B. C. H. Steele and A. Heinzel, Nature, 2001, 414, 345-352.

7 M. Shao, Q. Chang, J.-P. Dodelet and R. Chenitz, Chem. Rev., 2016, 116, 3594-3657.

8 G. Wu, K. L. More, C. M. Johnston and P. Zelenay, Science, 2011, 332, 443-447.

9 Y. Hu, J. O. Jensen, W. Zhang, L. N. Cleemann, W. Xing, N. J. Bjerrum and Q. Li, Angew. Chem., Int. Ed., 2014, 53, 3675-3679.

10 S. Guo and S. Sun, J. Am. Chem. Soc., 2012, 134, 2492-2495.

11 W. Wang, J. Luo, W. Chen, J. Li, W. Xing and S. Chen, J. Mater. Chem. A, 2016, 4, 12768-12773.

12 D. Guo, R. Shibuya, C. Akiba, S. Saji, T. Kondo and J. Nakamura, Science, 2016, 351, 361-365.

13 Z. Chen, D. Higgins, A. Yu, L. Zhang and J. Zhang, Energy Environ. Sci., 2011, 4, 3167-3192.

14 A. Serov, K. Artyushkova and P. Atanassov, Adv. Energy Mater., 2014, 4, 1301735.

15 M. Zhou, C. Yang and K.-Y. Chan, Adv. Energy Mater., 2014, 4, 1400840.

16 Z. K. Yang, Z.-W. Zhao, K. Liang, X. Zhou, C.-C. Shen, Y.-N. Liu, X. Wang and A.-W. Xu, J. Mater. Chem. A, 2016, 4, 19037-19044.

17 A. Zitolo, V. Goellner, V. Armel, M.-T. Sougrati, T. Mineva, L. Stievano, E. Fonda and F. Jaouen, Nat. Mater., 2015, 14, 937-942.

18 F. Jaouen, S. Marcotte, J. P. Dodelet and G. Lindbergh, J. Mater. Chem. B, 2003, 107, 1376-1386.

19 N. Ramaswamy, U. Tylus, Q. Jia and S. Mukerjee, J. Am. Chem. Soc., 2013, 135, 15443-15449. 
20 M. Lefevre, E. Proietti, F. Jaouen and J. P. Dodelet, Science, 2009, 324, 71-74.

21 W.-J. Jiang, L. Gu, L. Li, Y. Zhang, X. Zhang, L.-J. Zhang, J.-Q. Wang, J.-S. Hu, Z. Wei and L.-J. Wan, J. Am. Chem. Soc., 2016, 138, 3570-3578.

22 J. Masa, W. Xia, M. Muhler and W. Schuhmann, Angew. Chem., Int. Ed., 2015, 54, 10102-10120.

23 M. Eikerling, A. A. Kornyshev and A. R. Kucernak, Phys. Today, 2006, 59, 38-44.

24 Z. Xia, L. An, P. Chen and D. Xia, Adv. Energy Mater., 2016, 6, 1600458.

25 H.-W. Liang, X. Zhuang, S. Bruller, X. Feng and K. Mullen, Nat. Commun., 2014, 5, 4973.

26 H.-W. Liang, W. Wei, Z.-S. Wu, X. Feng and K. Muellen, J. Am. Chem. Soc., 2013, 135, 16002-16005.

27 Y. Wang, A. Kong, X. Chen, Q. Lin and P. Feng, ACS Catal., 2015, 5, 3887-3893.

28 L. Lin, Q. Zhu and A.-W. Xu, J. Am. Chem. Soc., 2014, 136, 11027-11033.

29 L. Lin, Z. K. Yang, Y.-F. Jiang and A.-W. Xu, ACS Catal., 2016, 6, 4449-4454.

30 Z. K. Yang, L. Lin and A.-W. Xu, Small, 2016, 12, 5710-5719. 31 S. Ji, H. Guo, X. Yuan, X. Li, H. Ding, P. Gao, C. Zhao, W. Wu, W. Wu and J. Zhao, Org. Lett., 2010, 12, 2876-2879.

32 S. J. Lee, S. S. Lee, M. S. Lah, J.-M. Hong and J. H. Jung, Chem. Commun., 2006, 4539-4541.

33 W. Li, G. Chen, S. Zhang, H. Wang and D. Yan, J. Polym. Sci., Part A: Polym. Chem., 2007, 45, 3550-3561.

34 J. Jin, F. Pan, L. Jiang, X. Fu, A. Liang, Z. Wei, J. Zhang and G. Sun, ACS Nano, 2014, 8, 3313-3321.

35 L. Zhao, Y. Wang and W. Li, RSC Adv., 2016, 6, 90076-90081.
36 J. Xue, L. Zhao, Z. Dou, Y. Yang, Y. Guan, Z. Zhu and L. Cui, RSC Adv., 2016, 6, 110820-110830.

37 A. Kong, X. Zhu, Z. Han, Y. Yu, Y. Zhang, B. Dong and Y. Shan, ACS Catal., 2014, 4, 1793-1800.

38 J. Shi, X. Zhou, P. Xu, J. Qiao, Z. Chen and Y. Liu, Electrochim. Acta, 2014, 145, 259-269.

39 D. Shin, B. Jeong, B. S. Mun, H. Jeon, H.-J. Shin, J. Baik and J. Lee, J. Phys. Chem. C, 2013, 117, 11619-11624.

40 Q. Z. Ren, J. W. Huang, Z. A. Zhu, L. N. Ji and Y. T. Chen, J. Porphyrins Phthalocyanines, 2001, 5, 449-455.

41 F. Jaouen, M. Lefevre, J. P. Dodelet and M. Cai, J. Mater. Chem. B, 2006, 110, 5553-5558.

42 F. Jaouen, J. Herranz, M. Lefevre, J.-P. Dodelet, U. I. Kramm, I. Herrmann, P. Bogdanoff, J. Maruyama, T. Nagaoka, A. Garsuch, J. R. Dahn, T. Olson, S. Pylypenko, P. Atanassov and E. A. Ustinov, ACS Appl. Mater. Interfaces, 2009, 1, 1623-1639.

43 G. Wu, C. M. Johnston, N. H. Mack, K. Artyushkova, M. Ferrandon, M. Nelson, J. S. Lezama-Pacheco, S. D. Conradson, K. L. More, D. J. Myers and P. Zelenay, J. Mater. Chem., 2011, 21, 11392-11405.

44 Q. Wang, Z.-Y. Zhou, Y.-J. Lai, Y. You, J.-G. Liu, X.-L. Wu, E. Terefe, C. Chen, L. Song, M. Rauf, N. Tian and S.-G. Sun, J. Am. Chem. Soc., 2014, 136, 10882-10885.

45 L.-B. Lv, T.-N. Ye, L.-H. Gong, K.-X. Wang, J. Su, X.-H. Li and J.-S. Chen, Chem. Mater., 2015, 27, 544-549.

46 L.-T. Song, Z.-Y. Wu, F. Zhou, H.-W. Liang, Z.-Y. Yu and S.-H. Yu, Small, 2016, 12, 6398-6406.

47 X. Zhou, Z. Bai, M. Wu, J. Qiao and Z. Chen, J. Mater. Chem. A, 2015, 3, 3343-3350. 